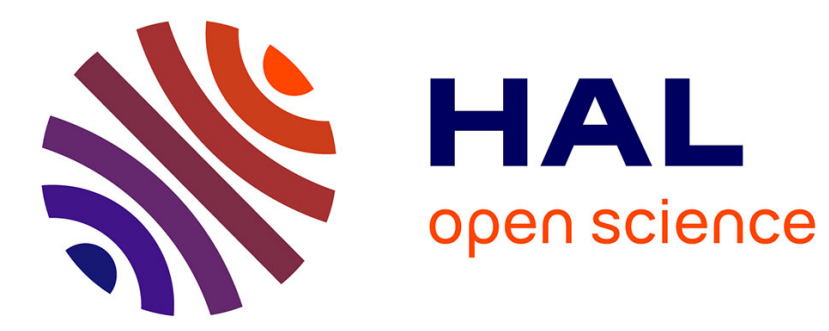

\title{
ULTRASONIC ATTENUATION IN STEELS DURING FATIGUE
}

\author{
Pan Zhengliang, Li Guangyi
}

\section{To cite this version:}

Pan Zhengliang, Li Guangyi. ULTRASONIC ATTENUATION IN STEELS DURING FATIGUE. Journal de Physique Colloques, 1985, 46 (C10), pp.C10-329-C10-332. 10.1051/jphyscol:19851073 . jpa-00225458

\section{HAL Id: jpa-00225458 https://hal.science/jpa-00225458}

Submitted on 1 Jan 1985

HAL is a multi-disciplinary open access archive for the deposit and dissemination of scientific research documents, whether they are published or not. The documents may come from teaching and research institutions in France or abroad, or from public or private research centers.
L'archive ouverte pluridisciplinaire HAL, est destinée au dépôt et à la diffusion de documents scientifiques de niveau recherche, publiés ou non, émanant des établissements d'enseignement et de recherche français ou étrangers, des laboratoires publics ou privés. 


\title{
ULTRASONIC ATTENUATION IN STEELS DURING FATIGUE
}

\author{
PAN ZHENGLIANG AND LI GUANGYI \\ Institute of Metal Research, Academia Sinica, Wenhua Road 2-6, \\ Shenyang, China
}

\begin{abstract}
The change of ultrasonic attenuation $\Delta \alpha$ as a function of fatigue cycle number $n$ correlates well with the length of fatigue crack. A depinning model of dislocations with kinks is suggested to interpret the experimental results.
\end{abstract}

\section{I - INTRODUCTION}

In the Ithaca Conference (1961), Hikata et al. /1/ reported that the ultrasonic wave can "see" the motion of dislocations. Sachs and Green /2/ have also researched the orientation dependence of dislocation damping. Some of the early work in this fleld was summarized by Truel1 et a1. /3/. In the last ten years increasing attention was paid to the effect of a blas stress on the ultrasonic attenuation in metal single crystals $/ 4-7 /$. It was seen that $/ 6 /$ the first motion of dislocation is controlled by the existence of the lattice friction stress (Peier1s-Nabarro stress). According to a mechanism of interaction between dislocation and point defects some typical shapes of $\Delta \alpha-\sigma$ curve have been explained and the connection with the low frequency internal friction spectrum has been established $/ 7 /$. Otherwise Wang et al. $/ 8 /$ have found that the interaction between ultrasonic shear wave and moving dislocation can give rise to second and third order harmonic waves.

II - EXPERIMENTAL PROCEDURE

The composition of the steels used in the present work is given in Table 1. After heat treatment the start materials were carefully ground to standard compactible

Table 1 Composition $(w t . \%)$ of Steels

\begin{tabular}{lccccccccc}
\hline No & Stee1 & $\mathrm{C}$ & $\mathrm{Cr}$ & $\mathrm{Mn}$ & $\mathrm{Si}$ & $\mathrm{Ni}$ & $\mathrm{P}$ & $\mathrm{S}$ & 0 \\
I & 30CrMnSiNi2 & 0.30 & 1.09 & 1.23 & 1.12 & 1.55 & $<0.006$ & $<0.002$ & \\
II & $9 \% \mathrm{Ni}$ Stee1 & 0.06 & & 0.19 & 0.20 & 9.1 & $<0.006$ & $<0.006$ & $<0.0037$ \\
\hline
\end{tabular}

tension test sample agreed w1th ASTM E399-74 and the grinding tolerance is more than $0.5 \mathrm{~mm}$. The thickness of the sample is $20 \mathrm{~mm}$ and the parallelism and planeness of the two opposite planes are approximately equal to $1 \times 10^{-4}$. 
The measurements of ultrasonic attenuation were carried out using the pulse echo method described elsewhere $19 \%$. We record the change of attenuation by means of a $X-Y$ recorder with an accuracy of $0.003 \mathrm{~dB} / \mu \mathrm{s}$. An X-cut quartz transducer with fundamental frequency $10 \mathrm{MHz}$ and diameter $10 \mathrm{~mm}$ was carefully coupled on one sample plane in contact with the crack tip. On the opposite plane of the sample the crack length was measured by means of a microscope. The frequency of fatigue was 95 and $150 \mathrm{~Hz}$ for steel I and II, but the frequency of $0.02 \mathrm{~Hz}$ was utilized to measure attenuation as a function of load P during cycle deformation. The upper and lower limits of fatigue load were chosen as $12 \mathrm{kN}$ and $4 \mathrm{kN}$ for stee? I, and $20 \mathrm{kN}$ and $4 \mathrm{kN}$ for steel II with an accufacy of $0.1 \mathrm{kN}$. After a certain number of fatigue cycles $\left(2 \times 10^{4}\right.$ for steel $I$ and $5 \times 10^{5}$ for steel II), the $\alpha-P$ were measured and the length of fatigue crack was observed under average static load.

\section{III - EXPERIMENTAL RESULTS}

The $\alpha-P$ curves for different cycle number $n$ are shown in Fig. 1 , in which the curves during loading and unloading are coincident with each other. The change of attenuation $\Delta \alpha$ during a cycle from Fig. 1 and the crack length a as a function of cycle number $n$ is shown in Fig. 2. It is clear that the $\Delta \alpha n$ curve is in good correlation with the a-n curve, and the variation of $\Delta \alpha$ is traced out during the period of crack nucleation. A similar result was obtained for steel II.

The a-P curves of steel $I$, shown in Fig. 3 , in the range of $n-12 \mathrm{kN}$ have been measured for different distance d between the disk of quartz and the tip of crack, when the fatigue crack had developed to the length $14 \mathrm{~mm}$. It is apparent that the attenuation decreases in the beginning period of loading and then drastically increases during loading over a critical load Pc and simitar (but less) varied during the subsequent unloading. So a hysteresis loop curve of attenuation is created in the region of smaller load. The critical load PC is approximately equal to 2, 4 and $6 \mathrm{kN}$ for $\mathrm{d}=0,0.8$ and $4 \mathrm{~mm}$ respectively. The total change of attenuation decreases with increasing distance d. The same hysteresis loop curves are also obtained during the cycle deformation with smaller load amplitude, such as $0-4 \mathrm{kN}$.

The steels I and II are respectively high and middle strength steel. Similar features of $\alpha-P$ curves for both steels were obtained, as in Fig. 4 , but the attenuation of steel II varied more smoothly during loading or unloading.

\section{IV - DISCUSSION}

A mechanism of dislocation breakaway $/ 5 /$ has been used to interpret the ultrasonic attenuation of dilute $A 1$ alloy and pure Al during bias stress experiment. Recently a model of geometric kink chain $/ 10$ / has been considered to calculate the attenuation as a function of bias stress. We suggest a combination of the two models, sketched in Fig. 5. The density of dislocations, and also the density of geometric kinks, is very high in tempering steels. The sidewise migration of the geometric kinks feasibly takes place under a small applied bias stress and the dislocation loops between pinning points can be bowed out, as in Fig. 5b, so that the length of dislocation segments vibrating under the stress of the ultrasonic wave is decreased, i.e. $L c(\sigma)<L c(0)$. As is well known $/ 3 /$, the ultrasonic attenuation due to dislocations is $\alpha \Lambda L^{4}$. It is explained that the attenuation decreases with increasing bias stress in the beginning period of loading. When the applied bias stress is over the critical value, the dislocation may break away from pinning points, then length LC catastrophically becomes the full network loop length Ln, and the attenuation drastically increases with increasing bias stress. The opposite process will take place during unloading, but near the critical stress the dislocation will not again be pinned, until dislocation loops move back near their equilibrium position, i.e. the length of dislocation loops is approximately equal to the original length $L c(0)$. Hence the change of attenuation is also smaller during unloading and a hysteresis loop of attenuation can be obtained in the region near the critical load during cycle deformation. 
The critical load should correspond to the stress under which a part of the dislocation breaks away from the pinning points under uitrasonic stress. As an examination of this model the distribution of stress near the quarts /11/ was calculated according to fracture mechanics. It was found that in about $5 \%$ f quartz area $\sigma_{\mu y}>10^{-2} \mu, \mu$ being shear modulus, when $P=P C$ in Figs. 3 and $4.10^{-2} \mu$ was generałyy referred as the breakaway stress of dislocations $/ 12 \%$. The $5 \%$ area is large enough to increase the total attenuation. The critical load in a-p curves is probably a useful parameter for investigating the behavior of dislocations during fat igue.

The effect of stress concentration around the crack tip on attenuation can be used to explain the result of Fig.2 . The increase of the length of crack during fatigue is accompanied by the extension of area in which the breakaway stress of dislocation is achieved, so that the $\Delta \alpha-n$ curve can be analogous to the a-n curve.

\section{REFERENCES}

/1/ Hikata, A., Chick, B., Elbaum, C. and Truell, R., Acta Metal1., 10(1962), 423.

12/ Saches, W. and Green Jr, R.E., Trans. TMS-AIME, 242(1968), 2185 .

/3/ True11, R., Elbaum, C. and Chick, B., Ultrasonic Methods in Solids State Physics, Academic Press, New York, (1969).

14/ Vincent, A. and Perez, J., IL Nuovo Cimento, 33B(1976), 147.

/5/ Vincent, A. and Perez, J., Phil. Mag., 40A(1979), 277.

16/ Deterre, Ph., Esnouf. C., Fantozzi, G., Peguin, P., Perez, J., Ritchie, I., Vanoni, F, and Vincent, A., Acta Metal1., 27(1979), 1779.

17/ Gremaud, G, and Benoit, W., I. de Physique, 42(1981), C5-163 and C5-369.

/8/ Wang, Y.T., Britton, W. G.B. and Stephens, R.W.B., J. de Physique, $42(1981)$, C5-387.

19/ Pan Zhengliang and Su Huihe, Acta Acustica (Sinica), 5(1979), 188.

/10/ Bujard, M. and Gremaud, G., J. de Physique, 44(1983), C9-673.

/11/ Pan Zhengliang, Wang Shuangguan and Li Guanyi, Acta Physica Sinica 34(1985), 134 .

112/ Hirth, J.P. and Lothe, J., Theory of Dislocations, 2nd Ed., John Wilay \& Sons, New York, 1982, p.674.

F1g. 1 Ultrasonic attenuation as a function of load during a cycle deformation for different number of fatigue cycle; a-g respectively indicate corresponding points of Fig. 2

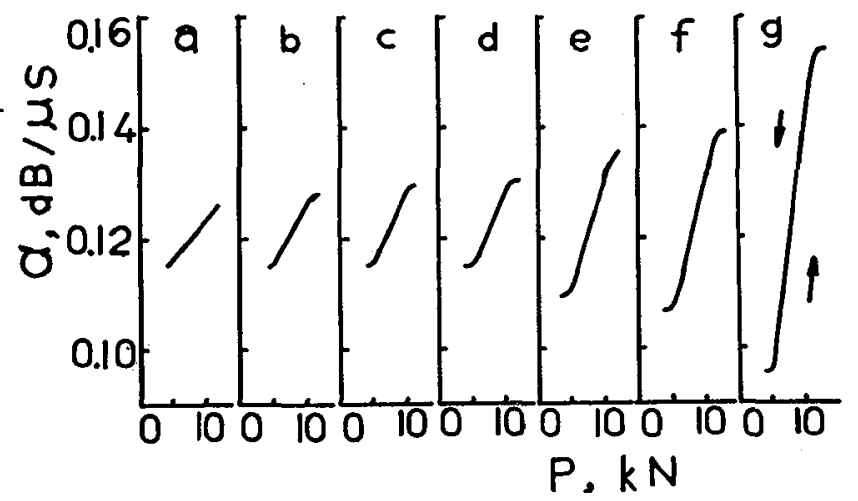




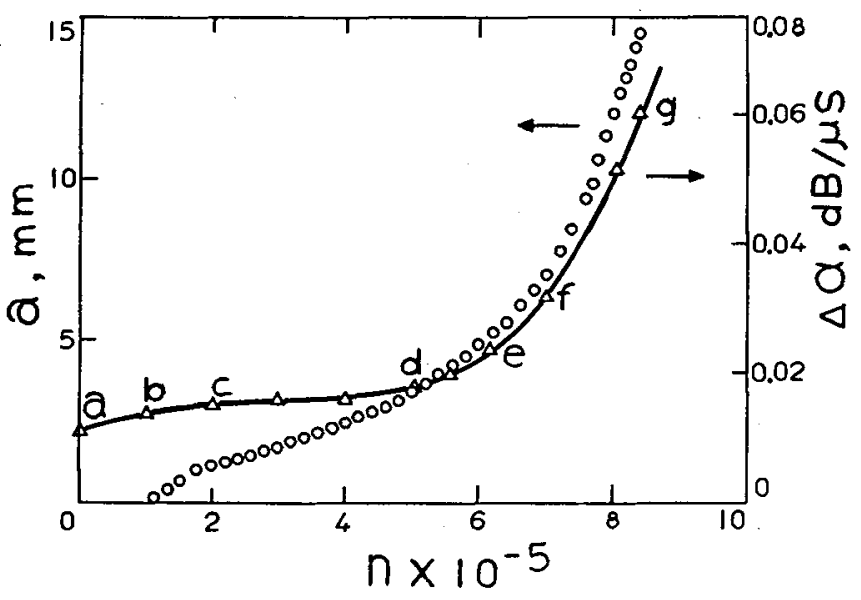

Fig.2 The length of fatigue crack $a$ and the change of ultrasonic attenuation $\Delta \alpha$ as a function of cycle number for steel I

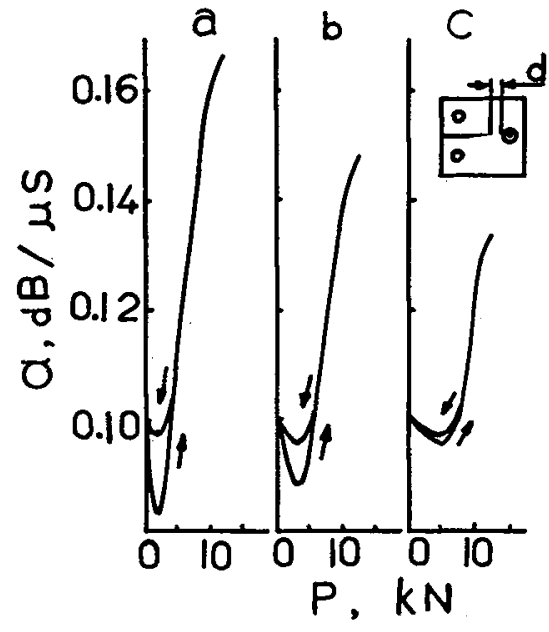

Fig.3 $\alpha-p$ curves for different distance d between the circle of quartz and the tip of crack for steel I

up right figure indicated the shape of sample,

- indicated quartz.

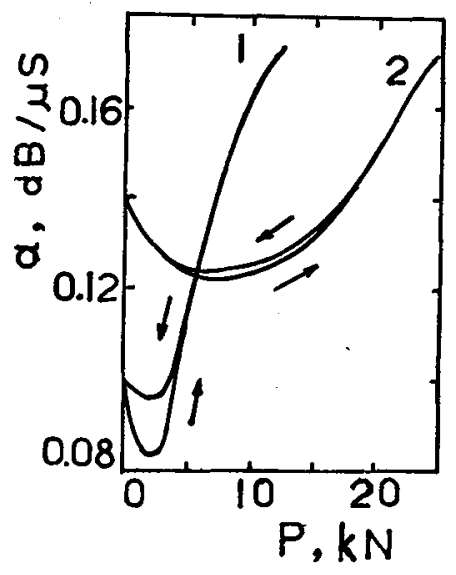

Fig. 4 Comparison of $\alpha-p$ curves between steel I and II

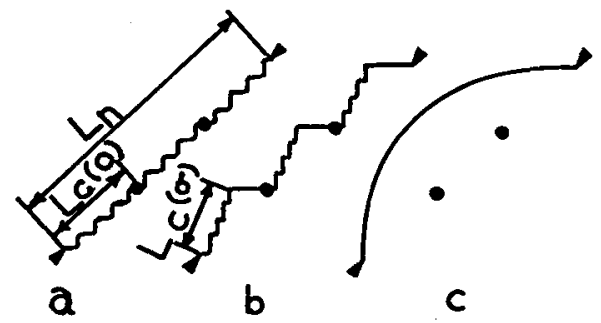

Fig.5 A model of dislocation break away

a) Initial configuration

b) dislocation bowing out and sidewise migration of geometric kinks

c) dislocation bréak away 